\title{
Lhermitte duclos disease: what to expect during surgery?
}

\author{
Sanjeev Kumar ${ }^{*}$ (D) Debabrata Sahana, Amit Jain, Lavlesh Rathore, Manish Tawari, Jatinder Mittal and Rajiv Sahu
}

\begin{abstract}
Lhermitte and Duclos first described the dysplastic gangliocytoma of the cerebellum in 1920. In the last 100 years, its clinical presentation, radiological features, pathological characteristics, and association with Cowden syndrome have been well described. However, documentation of surgical experiences is lagging. We here describe intraoperative experience during the removal of the tumor, which could help the operating surgeon plan and mental makeup.
\end{abstract}

Keywords: Lhermitte duclos disease, Dysplastic gangliocytoma, Tiger stripe disease

\section{To the Editor}

The present literature on Lhermitte Duclos Disease (LDD) focuses on its presentation, radiologic and pathological features [1-3]. They lack detailed intraoperative pictures, findings, and surgical nuances. Its rarity may perplex a young neurosurgeon regarding intraoperative differentiation between dysplastic and normal folia, vascularity, consistency, ease of removal, and radicalism of resection. We have focused here on filling in such details.

A 19-years male had undergone a ventriculoperitoneal shunt two years back for headache, visual blurring, and drowsiness at a peripheral hospital. There were no previous imaging records. Following resolution of the symptoms, he did not seek further treatment until eight months when the headache reappeared, and gait disturbances worsened progressively. Examination revealed truncal and appendicular ataxia, left upper limb dysmetria without papilloedema. Radiological evaluation showing characteristic "tiger stripe" appearance has been described (Figs. 1, 2, 3).

Surgery was planned in view of brainstem compression in a prone position. The Head was slightly turned to the opposite side and flexed to make the tent perpendicular to the floor (Fig. 4a). A left lateral sub-occipital craniotomy was made across the midline, including the foramen magnum's rim, up to the transverse and sigmoid sinuses (Fig. 4b) as the dura was tense, hyperventilation and decongestants were used before dural opening in a Y-shaped manner up to the transverse sinus to expose the tentorial surface (Fig. 4b). Cisterna-magna was drained for further relaxation. No lesion was visible on the suboccipital surface (Fig. 4c). On gentle retraction over the tentorial surface, pale white, widened folia could be distinguished from normal folia (Fig. 4d). Normal draining veins were seen entering the tentorial sinuses from dysplastic tissue. A normal-sized superior petrosal vein was seen.

Dysplastic folia were firm, rubbery, and not easily suckable but amenable to CUSA. The dysplastic tissue had low vascularity, but the vessels traversing between the folia were the source of hemorrhage. Subpial resection helped preserve veins. After significant decompression, the trochlear nerve, pre-central cerebellar vein, and vermian veins draining into the vein of the Galen complex

*Correspondence: ksanjeev79@gmail.com

Department of Neurosurgery, DKS Post Graduate Institute and Research

Center, Raipur, Chhattisgarh 492001, India 


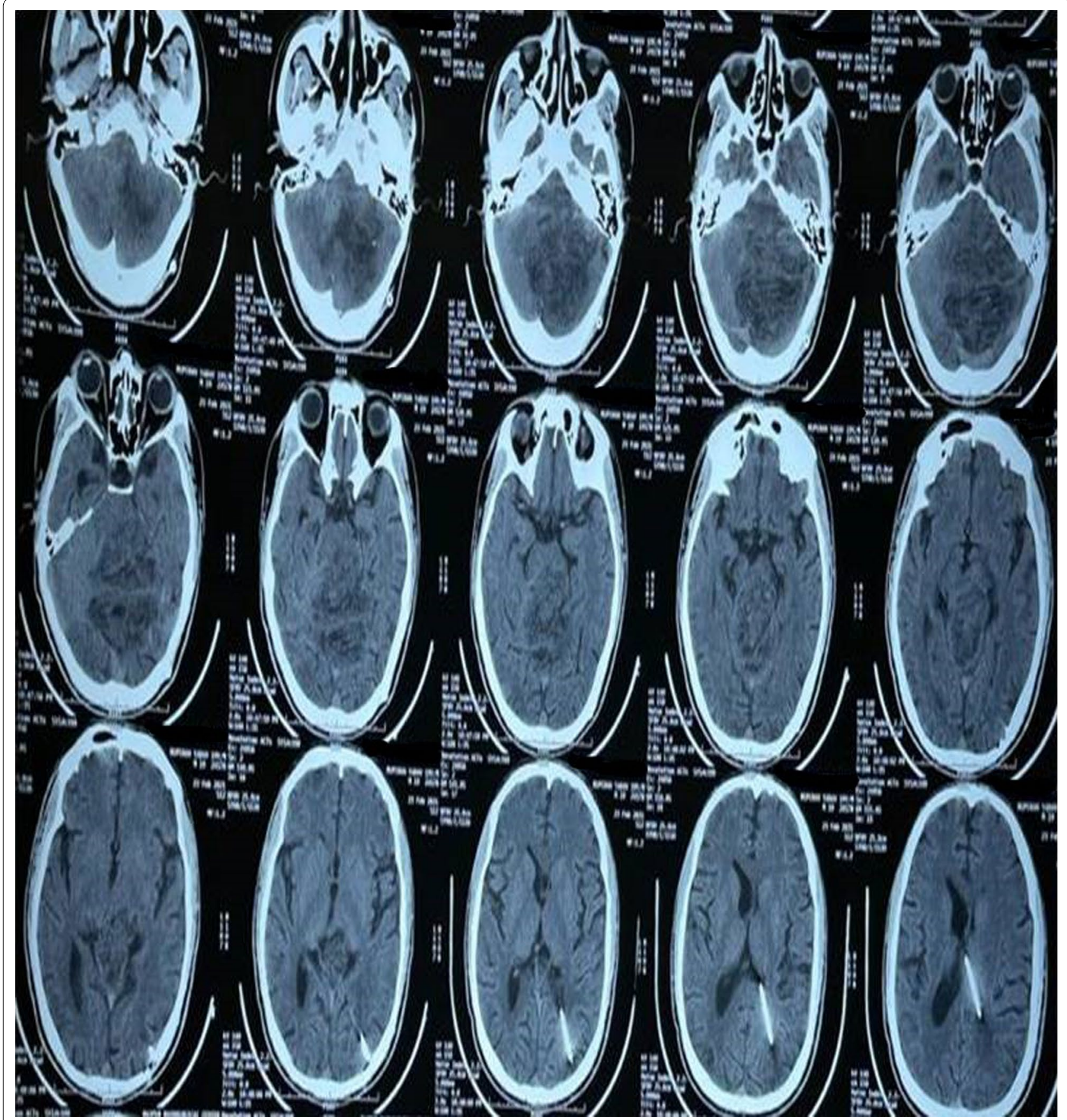

Fig. 1 Preoperative CT scan showing hypo-dense lesion involving left cerebellar hemisphere and vermis with bands of hyper-densities inside the lesion, compressing brainstem and non-visualization of fourth ventricle cavity, and presence of shunt inside the left lateral ventricle (Original)

were identifiable. We then focussed the microscope at the under-surface of the cerebellum for further tumor resection. The planes between dysplastic and normal folia were well-defined superficially but turned progressively indistinguishable based upon color, width, and consistency in the deeper areas of the inferior and anterior cerebellar surfaces, which precluded further resection. At the end of the surgery, the posterior fossa was lax. Dura was closed primarily, and the bone flap was replaced.

Postoperatively, there were no new neurological deficits. CT showed adequate decompression; however, the residual lesion was seen on T2WI MRI in the inferior 

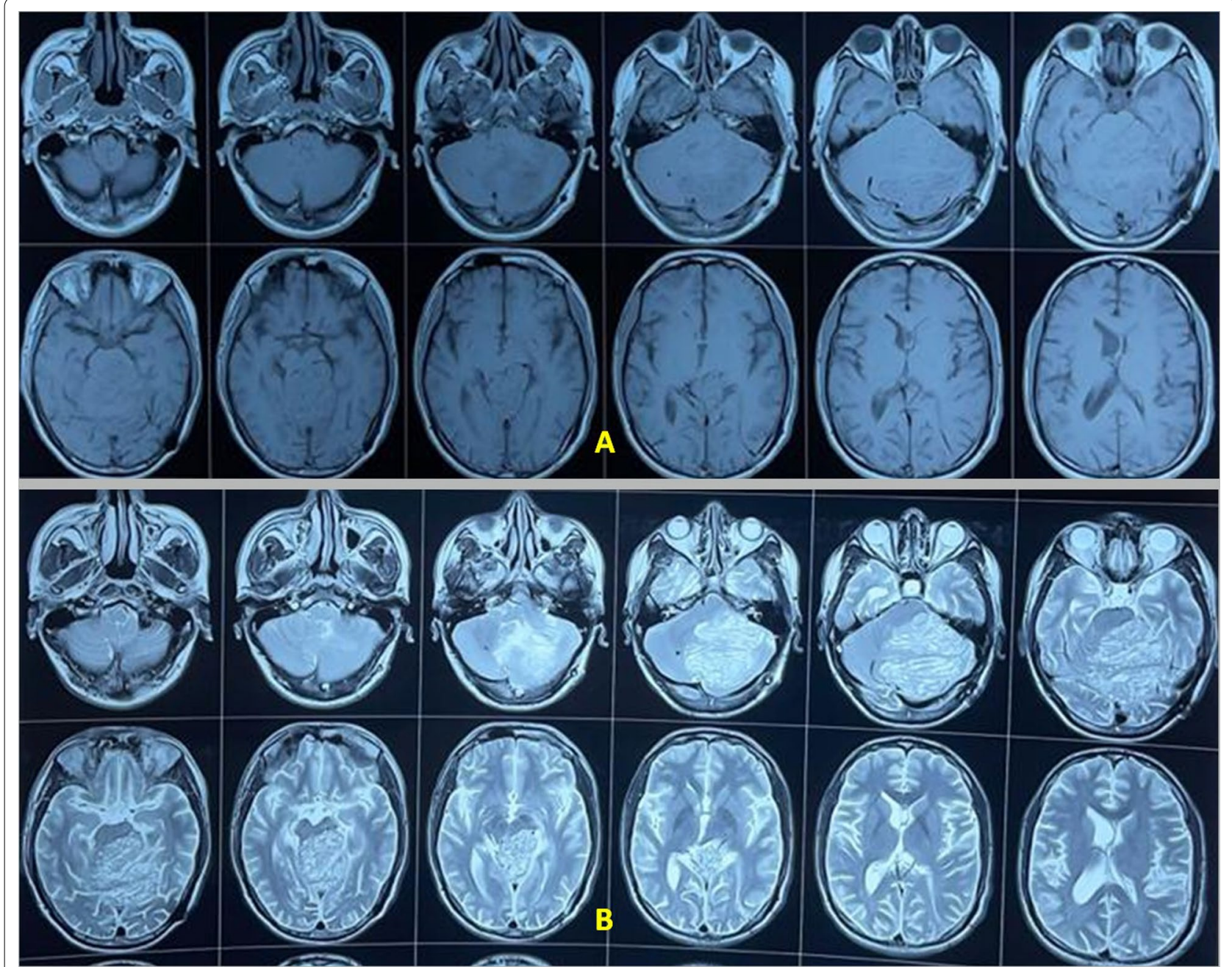

Fig. 2 Preoperative MRI scan. a T1WI shows hypo-intense lesion involving the tentorial and petrosal areas of the cerebellum, upper $2 / 3 \mathrm{rd}$ of the vermis, with an indentation on the brain stem. $\mathbf{b}$ T2WI shows a hyperintense lesion with alternating hypo-intense bands giving the characteristic "tiger stripe" appearance. There is thinned-out cerebellar parenchyma overlying the lesion. There is no perilesional edema (Original)

cerebellar regions (Fig. 5a, b). Histopathological examination and PTEN-positive mutation confirmed the diagnosis of LDD. At six months follow-up, here is a partial improvement in ataxia.

This pale white lesion [4] has a distinct plane superficially, but as one digs deeper surgical planes get obliterated, likely due to an "Arbor-Vitae" arrangement of cerebellar white matter. The dysplastic folia have a firm, rubbery, low-grade glioma-like consistency and may be held with forceps, but excessive pulling during dissection may damage the normal folia. Suctioning does not efficiently decompress the tumor, and CUSA is a boon. Cutting Bi-polar forceps may also serve the purpose.

Although the lesion itself has low vascularity, one should not presume it to be a bloodless procedure. The dysplastic folia do not enhance on contrast; streaks of enhancement inside the lesion denote traversing vessels between folia. Increased regional blood flow on perfusion-weighted MRI and hyper-metabolism in FDG-PET has been described [5]. Careful transgression across multiple sulcal spaces, harboring vessels, alleviates bleeding. Preservation of veins is of paramount importance as they drain normal cerebellar tissue along with the dysplastic ones. These veins may be preserved using subpial resection, especially towards the brainstem.

To the best of our knowledge, there is no published report for intraoperative ultrasonography use, aiding resections of LDD. Although we had not used it, we believe that the intraoperative ultrasonography could have helped detect the lesion and decide the margins. Similarly, no published report suggests the use of Fluorescence-guided resection in LDD. The intensity of 

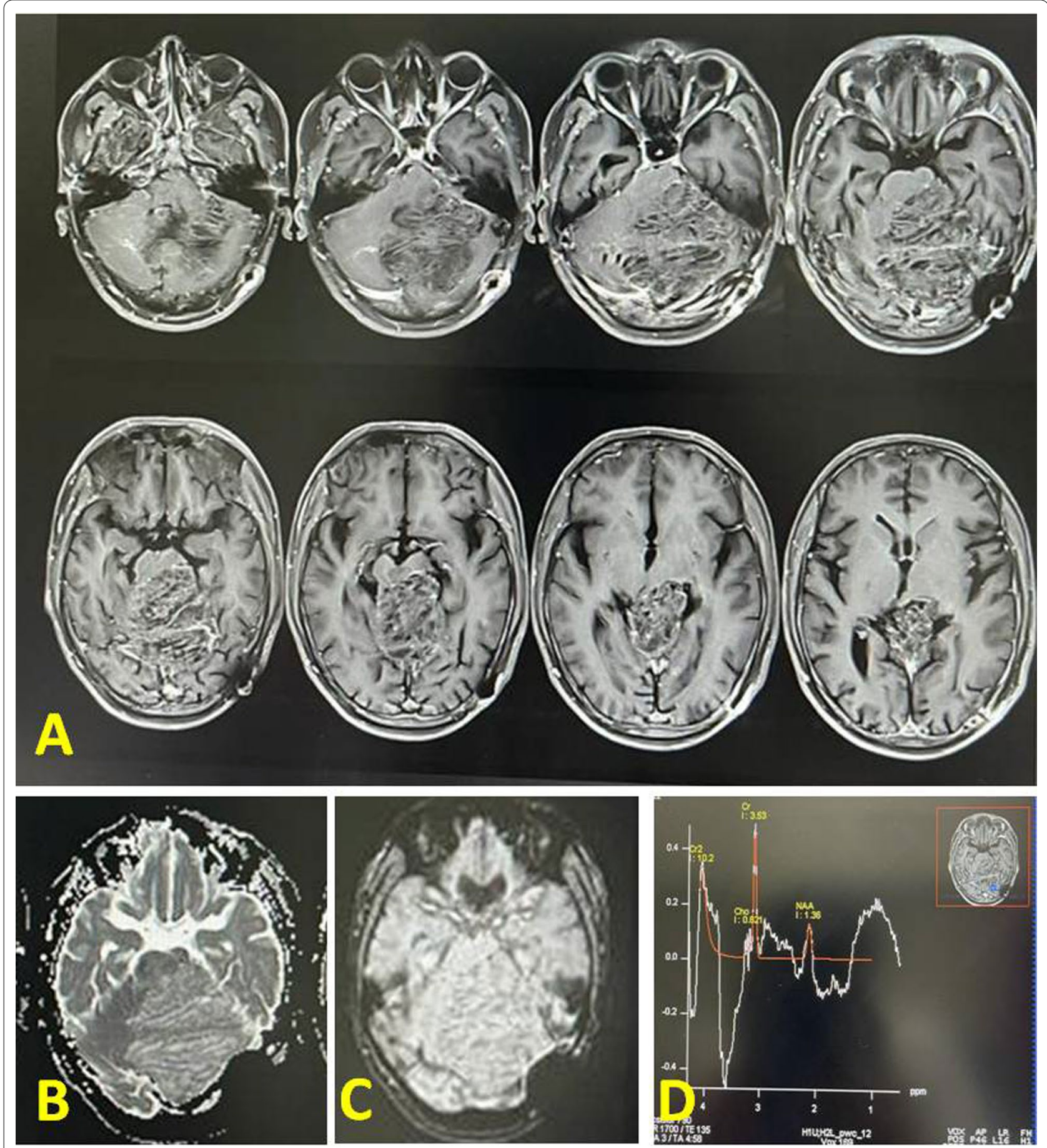

Fig. 3 MRI Characteristics of the lesion. a After contrast administration, multiple linear enhancing streaks were seen inside the lesion and at its periphery. $\mathbf{b}$ No diffusion restriction on DWI, $\mathbf{c}$ no blooming on SWI, d MR Spectroscopy shows decreased choline and NAA peaks (Original)

fluorescence correlates with tumor cell density, proliferation rate, vascularity, and blood-brain-barrier integrity. LDD is a grade I tumor with low proliferation rate, vascularity, and does not enhance on contrast, suggesting the intact blood-brain-barrier. We had not used fluorescent dye in this case and are unsure about its utility. Hydrocephalus in these patients occurs secondary to fourth ventricle compression. We 


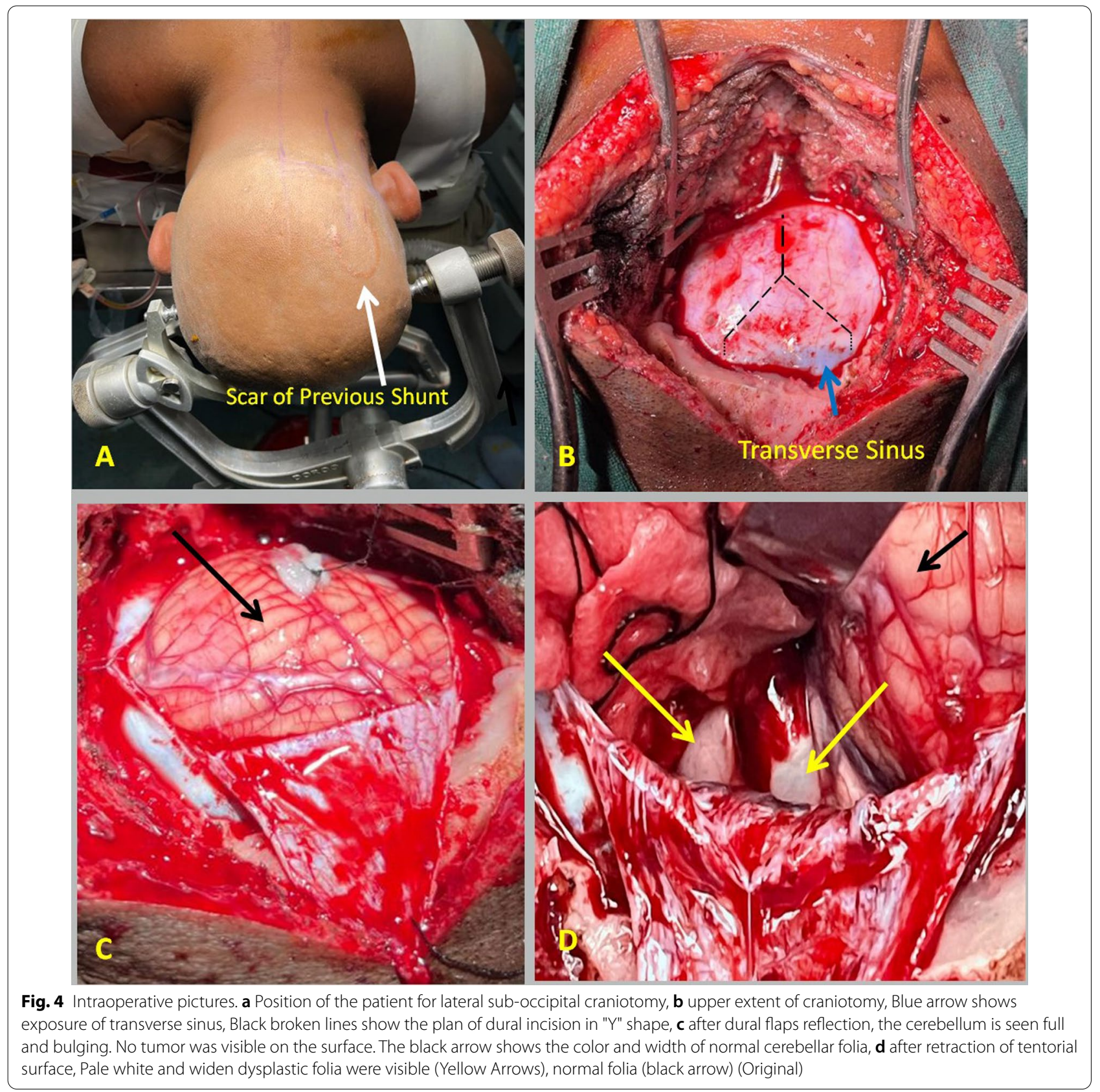

recommend direct tumor resection instead of CSF diversion.

LDD is a WHO grade-I tumor. Gross total resection is recommended but is often not possible [2]. The preoperative images of our patient showed thinned-out normal cerebellar parenchyma with intraoperative loss of plane of differentiation during resection. The decompression was therefore done conservatively to prevent damage of left-over functional cerebellar tissue. Recurrence after subtotal resection has been reported [1]. We plan to follow our patient with radiological evaluation and proceed accordingly. 


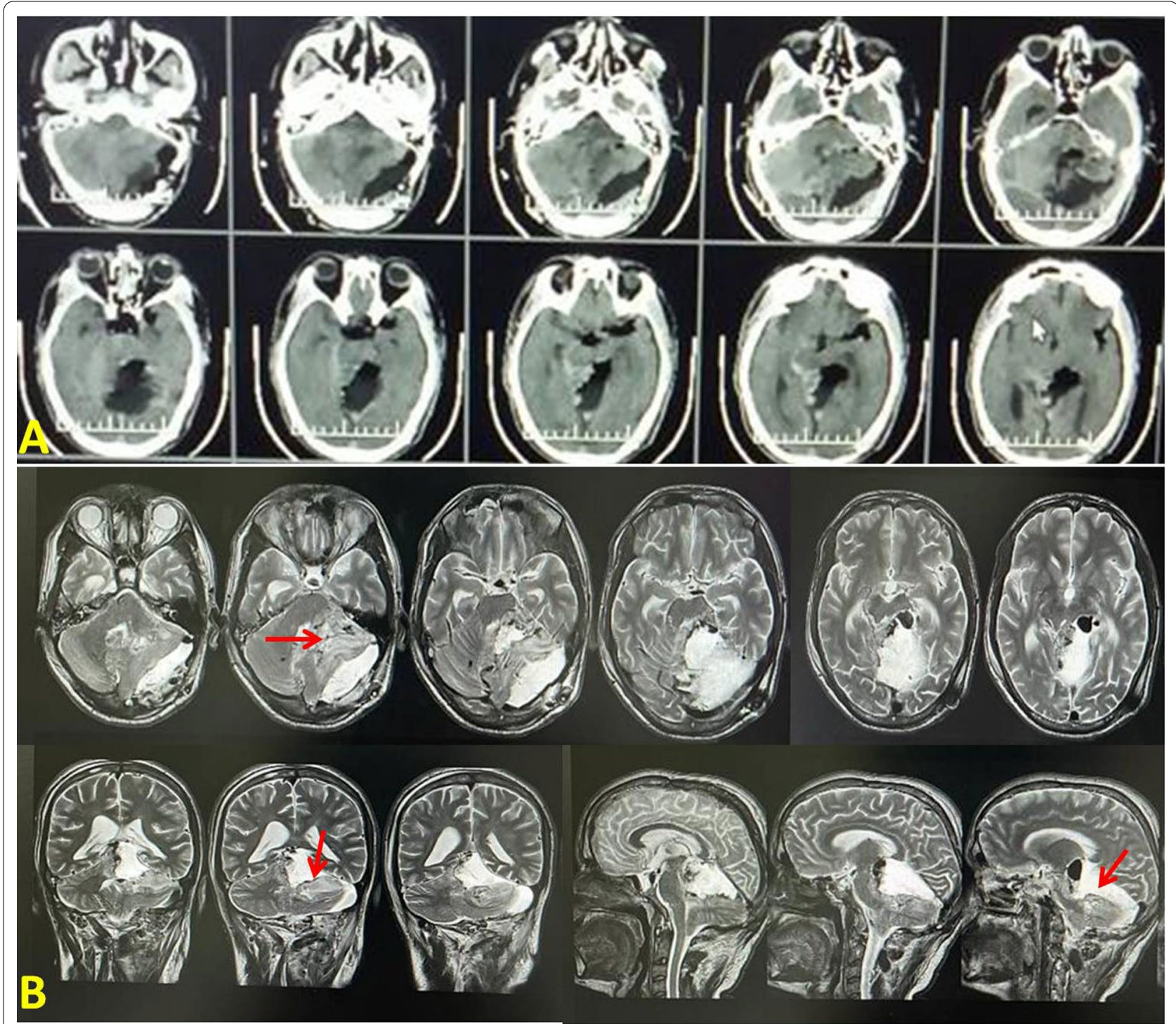

Fig. 5 Postoperative imaging. a CT scan shows adequate decompression, b T2WI showing residual lesion (red arrows) (Original)

\section{Abbreviations}

LDD: Lhermitte duclos disease; CT: Computed tomography; MRI: Magnetic resonance imaging.

\section{Acknowledgements}

Authors are sincerely thankful to Dr. Naman Chandrakar, Dr. Shashank Nahar Dr. Deepak Singh, Dr. Hemant Sharma, and Dr. Shipra Sharma for invaluable suggestions in preparing this manuscript.

\section{Authors' contributions}

SK and AJ were operating surgeons, SK, DS, LR, and MT conducted the literature search, SK, DS, and JM prepared the manuscript, SK, DS, and RS edited the final manuscript, MT and JM performed the follow-up of the patient. All the authors have read and approved the manuscript.

\section{Funding}

There is no source of funding.
Availability of data and material

Available with the authors.

\section{Declarations}

\section{Ethical approval and consent to participate}

The ethical approval was not needed and waived. The patient consented to participation.

\section{Consent for publication}

Written informed consent was obtained from the patient to publish this manuscript and any accompanying images

\section{Competing interest}

The authors declare that they have no competing interests. 
Received: 12 June 2021 Accepted: 11 September 2021

Published online: 30 November 2021

\section{References}

1. Abel TW, Baker SJ, Fraser MM, Tihan T, Nelson JS, Yachnis AT, et al. Lhermitte-Duclos disease: a report of 31 cases with immunohistochemical analysis of the PTEN/AKT/mTOR pathway. J Neuropathol Exp Neurol. 2005;64(4):341-9.

2. Nowak DA, Trost HA. Lhermitte-Duclos disease (dysplastic cerebellar gangliocytoma): a malformation, hamartoma or neoplasm? Acta Neurol Scand. 2002:105(3):137-45.

3. Giorgianni A, Pellegrino C, De Benedictis A, Mercuri A, Baruzzi F, Minotto R, et al. Lhermitte-Duclos disease. A case report Neuroradiol J. 2013;26(6):655-60
4. Ezgu MC, Ozer Ml, Dogan A, Deveci G, Kural C, Izci Y. Lhermitte-duclos disease in a six-year old child: a rare presentation. Pediatr Neurosurg. 2018:53(6):416-20.

5. Klisch J, Juengling F, Spreer J, Koch D, Thiel T, Buchert M, et al. Lhermitteduclos disease: assessment with MR imaging, positron emission tomography, single-photon emission CT, and MR spectroscopy. AJNR Am J Neuroradiol. 2001;22(5):824-30.

\section{Publisher's Note}

Springer Nature remains neutral with regard to jurisdictional claims in published maps and institutional affiliations.

\section{Submit your manuscript to a SpringerOpen ${ }^{\odot}$ journal and benefit from:}

- Convenient online submission

- Rigorous peer review

- Open access: articles freely available online

- High visibility within the field

Retaining the copyright to your article

Submit your next manuscript at $\boldsymbol{\nabla}$ springeropen.com 